\title{
EFFECTS OF RECRYSTALLIZATION ANNEALING ON MECHANICAL PROPERTIES OF COLD-ROLLED PDNI5 STRIPS
}

\author{
Aleksandra Ivanovic ${ }^{1 *}$, Biserka Trumić ${ }^{1}$, Svetlana Ivanov $^{2}$, Saša Marjanović $^{2}$, \\ Silvana Dimitrijević ${ }^{1}$, Vesna Marjanović ${ }^{1}$ \\ ${ }^{1}$ Mining and Metallurgy Institute Bor, Zeleni bulevar 35, 19210 Bor \\ ${ }^{2}$ Technical Faculty in Bor, University of Belgrade, Vojske Jugoslavije 12, \\ 19210 Bor
}

Received 12.01.2016

Accepted 08.03.2016

\begin{abstract}
The aim of this investigation was to determine the influence of the recrystallization temperature and recrystallization time on the microstructure and mechanical properties of the PdNi5 alloy subjected to cold deformation in the process of rolling at a constant deformation degree. The samples of PdNi5 alloy were recrystallization annealed within the temperature range of $200-1000^{\circ} \mathrm{C}$ and annealing time range of 20-45 min after cold rolling with deformation degree of $97 \%$. The tensile test was carried out using universal material testing machine. The hardness was also measured on the combined device for measuring Vickers and Brinell hardness. Metallographic observations were performed on an optical microscope. The analysis of the results of investigations regarding the microstructural changes and corresponding mechanical properties of cold-rolled PdNi5 strips shows that annealing temperature of $500^{\circ} \mathrm{C}$ was sufficient to activate the energy for various recrystallization processes causing a change in the mechanical properties of cold-rolled PdNi5 strips. The annealing time, at constant annealing temperature, almost did not affect a recrystallization temperature and the mechanical properties of the cold-rolled PdNi5 strips.

Key words: PdNi5 strips, Recrystallization, Mechanical properties, Cold deformation.
\end{abstract}

\footnotetext{
*Corresponding Author: Aleksandra Ivanović, aleksandra.ivanovic@irmbor.co.rs
} 


\section{Introduction}

Phase diagram of $\mathrm{Pd}-\mathrm{Ni}$ shows that these alloys form solid solutions across all composition range with minimum on the liquidus and solidus curve $\left(1273^{\circ} \mathrm{C}\right.$ at $\left.45 \% \mathrm{Pd}\right)$ [1]. The magnetic transformation extends from the Ni side almost to the Pd side, with a continuous decrease in temperature. No long-range order has been found in the $\mathrm{Pd}-\mathrm{Ni}$ alloys. However, a short range order was revealed in a single-crystal [2] and polycrystalline [3] samples by X-ray diffraction analysis. According to [2], the short range order is related to the formation of local ordered branched clusters in the form of rods, which are parallel to the $<100>$ axes and lie in the $\{100\}$ planes. The maximum degree of short-range order is reached after a prolonged annealing in the temperature range from 370 to $490^{\circ} \mathrm{C}$. No short range-order was observed in the alloys quenched from $600^{\circ} \mathrm{C}$ and higher.

Stoichiometric Pd-Ni alloys exhibit the existence of fine regions characterized by a high degree of the $\mathrm{Pd}_{3} \mathrm{Ni}$ - and $\mathrm{PdNi}_{3}$-type order [3]. Character of order and its degree remain unchanged in a temperature range from room temperature to $700^{\circ} \mathrm{C}$ [3] which is contrary to [2].

X-ray diffraction analysis and residual resistivity measurements are used to study the short-range order and fine crystal structure of the $\mathrm{Pd}-25$ at $\% \mathrm{Ni}$ solid solution deformed at room temperature and its changes during isochronous annealing. A shortrange order was shown to exist in the deformed alloy. During the annealing, the character of the order remains unchanged. Possible physical processes that cause the nonmonotonic changes in the short-range order, fine crystal structure parameters, and residual resistivity are considered [4].

Monte Carlo (MC) simulations with the embedded atom method (EAM) are set up and were used to investigate the segregation at PdxNi100- x(lll 100$),\left(\begin{array}{lll}1 & 1 & 0\end{array}\right)$ and (1 1 1) surfaces $(1 \leq x \leq 50)$ as a function of temperature [5]. Simulations in the temperature range from 600 to $1000 \mathrm{~K}$ show a pronounced segregation of $\mathrm{Pd}$ for all compositions, which is in agreement with the lower surface energy of Pd. At higher temperatures, the $\mathrm{Pd}$ segregation is less pronounced (exothermic segregation in disordered alloys). For Pd-richer alloys, the tendency for segregation is attenuated as the strain energy becomes less important.

Changes in hardness of $\mathrm{Pd}-5 \mathrm{Ni}$ alloy after homogenization annealing were analysed in order to determine the optimal conditions for a thermomechanical processing regime for this alloy [6]. By using the full factorial experimental design at three levels and analysing experimental data, a mathematical model was defined. In the investigated ranges of parameters: temperature $\left(800,900\right.$ and $\left.1000^{\circ} \mathrm{C}\right)$ and time of homogenization annealing (30,60 and $90 \mathrm{~min}))$, the obtained empirical equation can be applied for the prediction of system response.

Electric and magnetic behavior of the system Ni-Pd alloys were studied in the papers [7,8]. Perpendicular magnetic anisotropy of Pd/Ni-multilayers (MLs) with (111) and (100) orientations strongly depends on the crystal orientation. Thermodynamic properties of Ni-Pd system alloys were investigated in the temperature range 700 $1200^{\circ} \mathrm{C}$ [9]. Based on these studies, it was concluded that the excess entropies of mixing are positive for all compositions. This is considered to be the primarily result of ferromagnetic properties of the alloys. 
The structure and surface of Pd-Ni alloys have been studied by different techniques $[10,11]$. Stress-rupture curves are often used to specify the high temperature performance of structural materials. According to [12] pure platinum and palladium and their alloys, unlike nickel, do not suffer from a generic form of high temperature embrittlement or weakening due to exposure to environments containing oxygen. The rupture properties of high purity palladium strips at $1200^{\circ} \mathrm{C}$ were similar to those of the less purity. The catalytic activity of palladium is slightly changed by alloying with nickel [13-15]. Pure palladium is too soft to be used for chemical application in the production process of nitric acid [16]. Alloying palladium with nickel increases its mechanical properties significantly while the catalytic activity is not reduced.

The aim of this paper is to contribute to the establishment of a database of platinum metals, primarily a database on palladium and its alloys. For that purpose, the hardness, tensile strength and elongation were investigated as the function of annealing time and annealing temperature at a constant deformation degree.

\section{Experimental work}

All experimental investigations were carried out on PdNi5 samples with content of $\mathrm{Ni}$ in all samples $5 \mathrm{wt} \%$, Pd - purity $99,99 \%$ and $\mathrm{Ni}$ - purity $99,95 \%$. Palladium, used for for alloying, originated from the RTB Bor production of electrolytic copper, was obtained as a by-product. The additional refining treatment in the Mining and Metallurgy Institute was carried out in order to increase the purity of palladium. Impurities were: $\mathrm{Ag}, \mathrm{Cu}, \mathrm{Fe}, \mathrm{As}, \mathrm{Sb}$ and $\mathrm{Bi}$. In order to achieve better compacting of materials, Pd-powder and Ni-sheet metal were pressed in a hydraulic press with pressure of $270 \mathrm{daN} / \mathrm{cm}^{2}$.

Melting of PdNi5 alloy was carried out in the medium frequency induction furnace, in the $\mathrm{MgO}$ crucible, size $\mathrm{h}_{1} \times \mathrm{h}_{2}=85 \times 80 \mathrm{~mm}, \mathrm{~d}_{1} \times \mathrm{d}_{2}=65 \times 55 \mathrm{~mm}$. The casting temperature of the PdNi5 alloy was $1520^{\circ} \mathrm{C}$. Molten batch was overheated before casting for $150-170^{\circ} \mathrm{C}$. Casting was done in graphite mold, pre-heated at a temperature of $350-400^{\circ} \mathrm{C}$. Homogenization annealing of samples was carried out in an electric resistance furnace of chamber type $\mathrm{LP} 08$ at $900^{\circ} \mathrm{C}$ for 30 minutes according to results of previous research $[6,17]$. Cold-rolling of samples was performed on the two-cage rolling mills for wire, from $200 \times 120 \mathrm{~mm}$ to the dimensions of $1.7 \times 1.7 \mathrm{~mm}$. After the rolling, PdNi5 alloy samples, in the form of strip, with the deformation degree of $97 \%$, were subjected to recrystallization annealing in the temperature range of $200-1000^{\circ} \mathrm{C}$ and annealing time range of 20-45 $\mathrm{min}$.

Hardness measurement was performed on the combined device for measuring the hardness by Vickers and Brinell, WPM (Werkstoffprüf-maschinen), Leipzig, Germany, with an applying force of $200 \mathrm{daNmm}^{-2}$.

Mechanical characteristics of wire $(\mathrm{Rm}$ and $\mathrm{A})$, were tested on a universal material testing machine Instron 1332, applying load of $100 \mathrm{kN}$. The strips were tightened by mechanical jaws and stretched with a speed of $10 \mathrm{~mm} / \mathrm{s}$. Prior to testing all specimens were cut to a length of $150 \mathrm{~mm}$.

Chemical analysis of samples was done on the atomic absorption spectrometer (AAS, Produced by: Perkins \& Elmer, Model: 403, Detection limit: $<0,0001 \mathrm{~g} / \mathrm{dm}^{3}$ ).

Microstructural testing of the alloy was done on samples with a diameter of 20 $\mathrm{mm}$ and $5 \mathrm{~mm}$ in height. The samples were prepared according to standard procedure grinding, polishing (polishing machines ROWA E-KG) with $0,05 \mu \mathrm{m} \mathrm{Al}_{2} \mathrm{O}_{3}$ powder and 
etched a few seconds with solution of $1 \mathrm{~g} \mathrm{CrO}_{3}+20 \mathrm{ml} \mathrm{HCl}$ to reveal the microstructure. Optical microscopy was performed on metallographic microscope EPYTIP 2, with magnification of 200 to $400 x$.

\section{Results and discussion}

The results of dependence of Vickers hardness of cold deformed samples, on annealing temperature and time, for $\varepsilon=97 \%$, are shown in Figure 1 . The results of dependence of tensile strength, Rm, on annealing temperature and time, for $\varepsilon=97 \%$, are shown in Figure 2. The results of dependence of elongation, A, on annealing temperature and time, for $\varepsilon=97 \%$, are shown in Figure 3. The results of microstructural testing are shown in Figure 4.

Based on the presented results of hardness changes as a function of annealing temperature (Fig. 1) it can be concluded that the hardness values of the cold deformed alloy for temperatures below $400^{\circ} \mathrm{C}$ do not change, but internal stresses are removed. There are no structural changes compared to the structure of the cold-deformed sample, which was documented by metallographic tests (Fig. 4a). Concerning the recovery interval of crystals, there is a slight decrease in hardness in the temperature range of $400-500^{\circ} \mathrm{C}$, due to the removal of internal stresses as well as the recovery of the crystal structure by removing small defects in the lattice caused by the increased speed of diffusion of atoms. At $500^{\circ} \mathrm{C}$ hardness decreases sharply which indicates that a texture change occurred, i.e. a new structure has been formed. The newly formed structure, during the primary recrystallization which occurs in a narrow temperature range from $500-600^{\circ} \mathrm{C}$, is polygonal with unstrained grains (Fig. 4b). Further increase of the annealing temperature above $600^{\circ} \mathrm{C}$ leads to a gradual, but quite small, hardness decrease, due to an increase in grain size, which is a sign of secondary recrystallization (Fig. 4c).

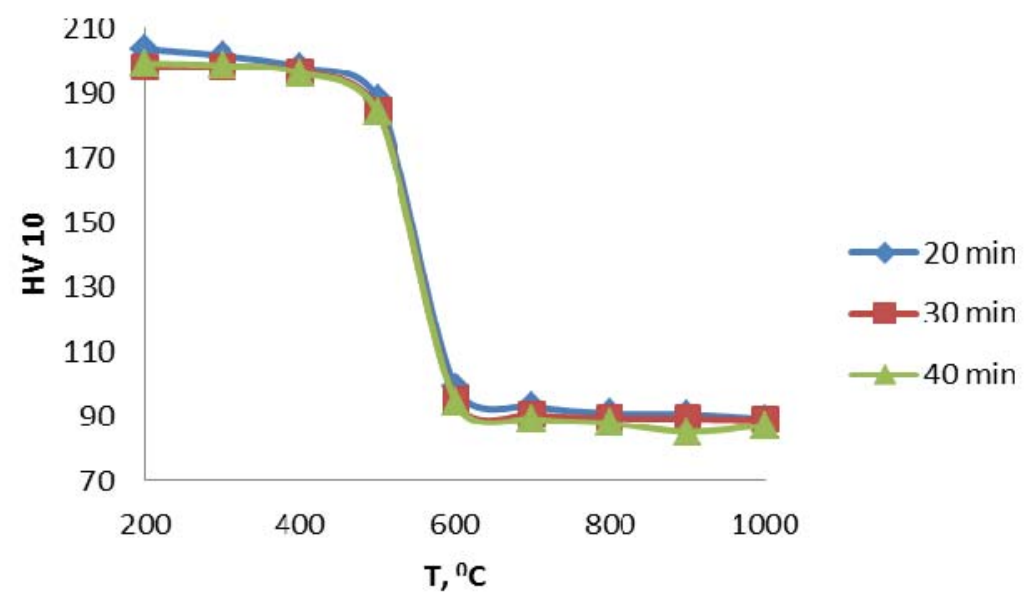

Fig. 1. Dependence of PdNi5 hardness on annealing temperature and annealing time 


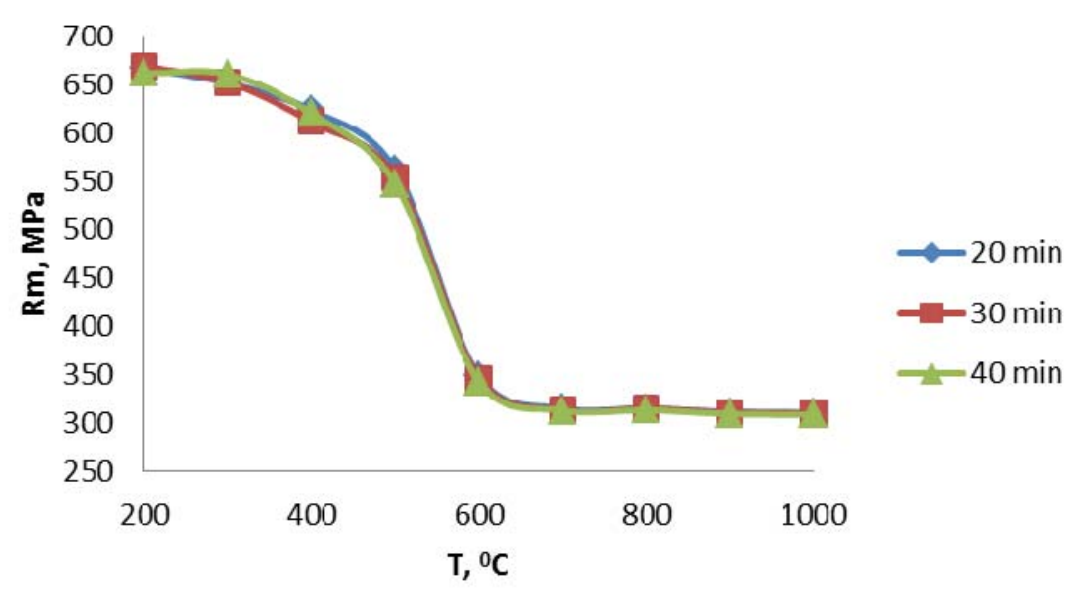

Fig. 2. Dependence of tensile strength on annealing temperature and annealing time

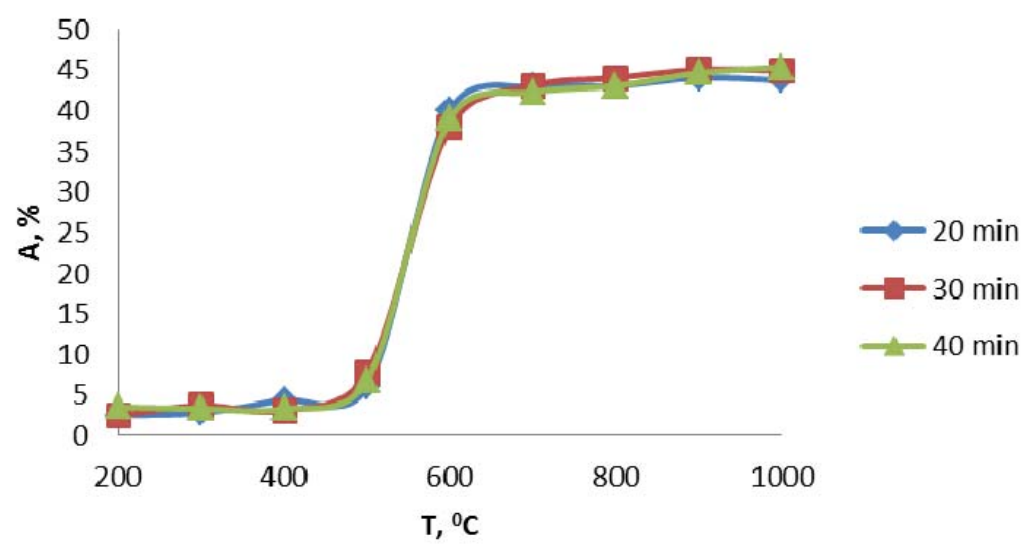

Fig.3. Dependence of elongation on annealing temperature and annealing time

Based on the results of tensile strength changes as a function on annealing temperature (Fig.2) it can be seen that the tensile strength of cold-worked and differently heated PdNi5 alloy samples in the form of strip does not change continuously with increase of temperature annealing. Tensile strength practically does not change up to the temperature of $400^{\circ} \mathrm{C}$, while in the temperature range $400-500^{\circ} \mathrm{C}$ there is a slight decrease in its values. This is a result of reducing the concentration of errors and their redistribution in the lattice. At $500^{\circ} \mathrm{C}$ there is a sharp decrease of tensile strength. This change takes place in a very narrow temperature range $\left(500-600^{\circ} \mathrm{C}\right)$ and is the result of progression of the recrystallization process and the formation of a new, undeformed structure, which is registered by metallographic examination (Fig. 4b). Increase of the annealing temperature above $600^{\circ} \mathrm{C}$ leads to grain growth which causes a further slight decrease in tensile strength as a consequence of the occurrence of secondary recrystallization, characterized by coarsening of the structure (Fig.4c). 
From the results of relative elongation changes as a function of annealing temperature (Fig. 3) it can be seen that the relative elongation with an increase in the annealing temperature to $400^{\circ} \mathrm{C}$ practically does not change, while in the temperature range $400-500^{\circ} \mathrm{C}$ there is a slight increase in the values of relative elongation. At $500^{\circ} \mathrm{C}$ a rapid increase in the relative elongation values occurs. Further increase of the annealing temperature, above $600^{\circ} \mathrm{C}$, causes a slight increase in the relative elongation. Considerations related to the causes of the of tensile strength behavior apply also for the relative elongation changes.

It was also observed that time of recrystallization annealing insignificantly affects recrystallization temperature, and thus the mechanical properties of the alloy PdNi5. The values of the mechanical characteristics ( $\mathrm{HV}, \mathrm{Rm}$ and $\mathrm{A}$ ) almost have identical values for different times at the same annealing temperatures.

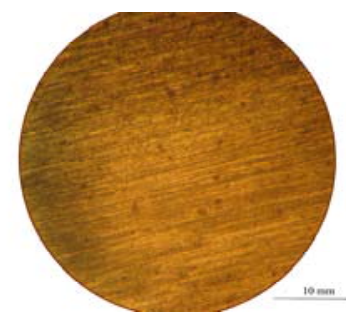

a)

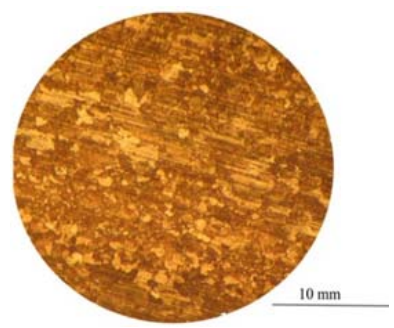

b)

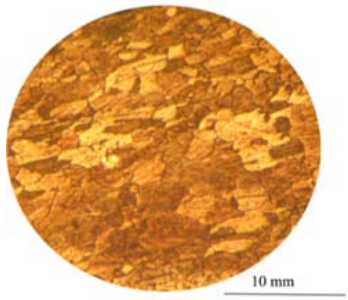

c)

Fig. 4. Optical microphotographs of the alloy with deformation degree $97 \%$, after annealing for 30 minutes at: (a) $500^{\circ} \mathrm{C}$, (b) $700^{\circ} \mathrm{C}$, (c) $900^{\circ} \mathrm{C}$. The samples are waterquenched.

The energy that accumulates during deformation renders cold-worked metal thermodynamically unstable. Therefore, there is a tendency that cold-worked metal returns to a state with lower Gibbs energy, which is closer to equilibrium-undeformed state. This transition is caused by a number of mechanisms associated with thermal mobility of atoms of the crystal lattice, with the diffusion processes, recreep of dislocations, transverse slide of dislocations $[18,19]$. These processes gradually activate during alloys heating, leading to a reduction in the orientation of the metal grains distorted parts of structures and restoring the properties to a state similar to that before deformation.

In presented case, for all samples, regardless of the duration of the recrystallization annealing process, annealing temperature of $500^{\circ} \mathrm{C}$ was sufficient to produce the necessary for activation of various processes causing changes in the mechanical properties of the PdNi5 alloy. As a result, there has been a decline in the value of the hardness and tensile strength, at the expense of an increase in elongation as a function of annealing temperature.

Real contribution of these investigations results is precise determination of heat treatment parameters in processing of platinum metals in Mining and Metallurgy Institute Bor. 


\section{Conclusion}

By analyzing the obtained results of tests conducted on PdNi5 alloy samples it can be concluded the following:

- By testing the hardness of PdNi5 alloy samples as a function of annealing temperature, for the deformation degree of $97 \%$, it was observed a sudden decrease corresponding to the recrystallization temperature.

- Annealing time almost did not affect recrystallization temperature, and, therefore, the mechanical properties of the PdNi5 alloy samples.

- In the temperature range of $400-500^{\circ} \mathrm{C}$, which is an interval of recovery of crystals, there is a slight decline in the values of hardness and tensile strength, while the relative elongation values slightly increase. These changes are the consequence of the removal of internal stresses as well as the recovery of the crystal structure.

- Due to the progression of the recrystallization process and the formation of a new, undeformed structure at $500^{\circ} \mathrm{C}$ there is a rapid decline in the values of hardness and tensile strength with a simultaneous increase in the relative elongation values. These changes take place in a very narrow temperature range of $500-600^{\circ} \mathrm{C}$.

- Further increase of the annealing temperature above $600^{\circ} \mathrm{C}$ leads to the gradual, but quite small, decline in the values of hardness and tensile strength with a simultaneous slight increase in the relative elongation as a result of the occurrence of secondary recrystallization.

\section{Acknowledgement}

The research results presented in this paper are the result of technological development project TR 34029 "Development of production technology of Pd catalystcatchers to reduce losses of platinum in high temperature catalysis processes", funded by the Ministry of Education, Science and Technological Development of the Republic of Serbia.

\section{References}

[1] http://resource.npl.co.uk/mtdata/phdiagrams/ nipd.htm, accessed in January 2016.

[2] W. Lin and J. E. Spruiell, Acta. Metall. 19(5) (1971) 451-561.

[3] A. A. Katsnel'son, I.I. Popova, Ukr. Fiz. Zh. (Russ. Ed.) 14(10) (1969) 1651-1654.

[4] P. V. Petrenko, A. V. Gavrilyuk, N. P. Kulish, N. A. Mel'nikova and Yu. E. Grabovskii, The Phys. of Metals and Metallogr., 108(5) (2009) 449-454.

[5] S. Helfensteyn, J. Luyten, L. Feyaerts, C. Creemers, Appl. Surf. Sci. (212-213) (2003) 844-849.

[6] A. Ivanović, B. Trumić, S. Ivanov, S. Marjanović, Hem.Ind. 68(5) (2014) 597-603.

[7] H. Takahashi, S. Fukatsu, S. Tsunashima, S. Uchiyama, J. Magn. Magn. Mater. 104-107(3) (1992) 1831-1832.

[8] A Tari, B. R. Coles, J. Phys. F: Met. Phys. 1(6) (1971) L69.

[9] L. R Bidwell, R Speiser, Acta Metall. 13(2) (1965) 61-70.

[10] A. V. Evteev, E. V. Levchenko, I. V. Belova, G. E. Murch, Defect and Diffusion Forum, 277 (2008) 207-212.

[11] M. Kasprzak, D. Baither and G. Schmitz, Acta Mater. 59(4) (2011) 1734-1741.

[12] P. G. Boswell, Platinum Met. Rev. 26(1) (1982) 16-19. 
[13] Z. Liu, X. Zhang, L.Hong, Electrochem. Commun., 11(4) (2009) 925 -928.

[14] C. Qiu, R. Shang, Y. Xie, Y. Bu, C.Li, H. Ma, Mater. Chem. Phys. 120(2-3) (2010) 323-330.

[15] C. Du, M. Chen, W. Wang, G. Yin, P. Shi, Electrochem. Commun., 12(6) (2010) 843-846.

[16] G. Raykhtsaum, L.Garner, Platinum Met. Rev., 57(3) (2013) 202-213.

[17] A. T. Ivanovic, B. T. Trumic, N. S. Vukovic, S. R. Marjanovic, B. R. Marjanovic, J. Optoelectron. Adv. Mater. 16(7-8) (2014) 925 - 932.

[18] B. Perovic, Physical Metallurgy, University of Montenegro, Faculty of Metallurgy and Technology, Podgorica, 1997.

[19] A. Ivanović, B. Trumić, S. Ivanov, S. Marjanović, S. Dimitrijević, V. Marjanović, Proceedings, Metallurgical \& MaterialsEngineering Congressof South-East Europe (MME SEE). Eds: M. Korać, 03.-05. 06. 2015, Belgrade, Serbia, pp. 231-237, 